\title{
FULLY VARIABLE, SIMPLE AND EFFICIENT - ELECTROHYDRAULIC - VALVE TRAIN FOR RECIPROCATING ENGINES
}

\author{
Wolfgang Schneider* \\ W. Schneider Ingenieurbüro, Dufourstrasse 3, 3600 Thun, Switzerland \\ Bieri Hydraulik AG, Könizstrasse 274, 3097 Liebefeld, Switzerland \\ * Corresponding author: Tel.: +41 7939259 71; E-mail address: wolfgang.schneider@bluewin.ch
}

\begin{abstract}
A new camless electrohydraulic valve train concept for combustion engines was developed at Empa (Swiss Federal Laboratories for Materials Science and Technology, Dübendorf, Switzerland) and tested on a spark ignition passenger car engine. Besides full flexibility with regard to lift and timing of the engine gas exchange valves it features robustness, simplicity and in particular a low own drive power need due to a maximum of hydraulic energy recuperation. The engine test results confirm substantial efficiency gains in classical as well as in hybrid power trains while also maintaining additional advantages. The system also has the potential to become a key element for load control of piston based compressors and expanders, reciprocating Joule Cycle engines and derivable future electricity storage systems.
\end{abstract}

Keywords: Variable Valve Actuation (VVA), Electro-Hydraulic Valvetrain System (EHVS)

\section{INTRODUCTION}

Besides defossilization with low carbon or synthetic fuels, a continuous improvement of internal combustion engines is one way to reduce the $\mathrm{CO}_{2}$ emissions of vehicles and for this a fully flexible valve train is essential. Today's series production solutions all are cam-based meaning valve lift and timing not being controllable independently, cylinder deactivation may not be integrated and still the effort for these approaches is not negligible. Despite numerous attempts no full camless systems - neither electric [2] nor electrohydraulic system [3-8] - have reached series-production [1]. Only one mass-produced electorhydraulic system uses a cam shaft with a hydraulic link [9] and finally one system is supposed to be near series production [10].

Empa - in close cooperation with the W. Schneider Ingenieurbüro - undertook a fresh approach for an electrohydraulic valve train. It was named "Flexwork" and actually serves as a development tool but also offers potential for industrial scale-up.

\section{IMPORTANT REQUIREMENTS AND DESIGN CONSIDERATIONS}

Lifting the engine torque curve throughout the whole speed range by optimizing inlet valve closing timing and valve overlap always is of interest. The first impact on the efficiency of an Otto engine however is load control by "dethrottling", meaning the air metering is controlled by - ideally fast and near digital early or late valve closing instead of the throttle device. Internal exhaust gas recirculation (EGR) can be optimized by controlling the valve overlap during gas exchange. So the outlet valves flexibility is of interest as well. Finally complete cylinder deactivation asks for cylinder individual valve control. Last but not least the own drive power need must be as low as possible.

In the past some electrohydraulic solutions had not been far from series realization. Breaking technologies always have difficulty in pushing out existing ones which are supported by their well implemented production processes. A new system has to make a considerable improvement step - preferably based on a low sophistication level and reasonable cost.

Control may have been too sophisticated in existing attempts. For a new approach the fast movement of the gas exchange valves - allthough disturbed by e.g. varying gas pressures - should not need fast sensor based control which in return would ask for highly responsive and expensive 
actuators.

As in cam drives quite a portion of energy is given back to the camshaft by the valve springs a low energy demand for the hydraulic drive is a real challenge. It could be attained by

- minimizing throttling in valves and fluid passages

- minimizing capacitive losses (small dead volumes, high fluid bulk modulus)

- adapting to demand (gas exchange lift)

- recuperating hydraulic energy

Last but not least an easy and universal applicability, also on existing engines, without the need of severely modifying the cylinder heads, is mandatory.

\section{THE DEVELOPED SYSTEM}

\subsection{Hydraulic Layout}

The developed system puts the challenges into practice by making use of an "asymmetric hydraulic pendulum" (Figure 1).

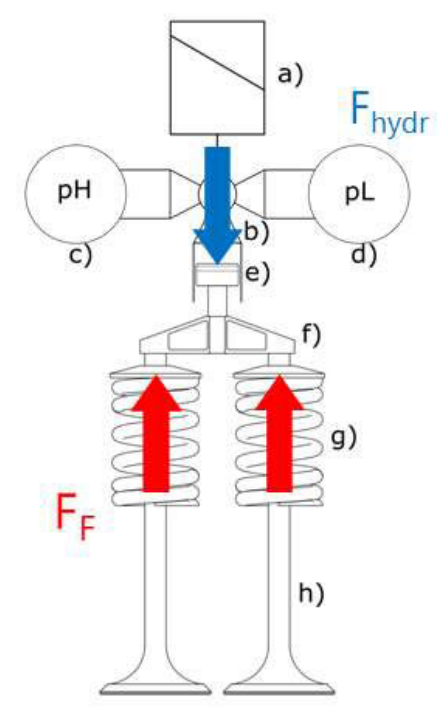
a) Solenoid
b) Hydraulic Valves
c) High pressure level
d) Low pressure level
e) Actuator piston
f) Valve bridge
g) Valve springs
h) Valves

Figure 1: general layout

One advantage of this layout is that the pushing piston allows a clear separation between the valve deck and the actuation deck.
This system does nothing but push a hydraulic piston with a given pressure to accelerate the gas exchange valves against its valve springs. The valves will "fly" in best case to the double of the static force balance point Figure 2.

The system is similar as described in [8] but uses a simple check valve as a hydraulic latch (see Figure 5a), thus keeping the valve inavoidably - in the attained position and conserving the stored kinetic energy to the maximum extend (pressure will jump up at the end of the stroke).

To achieve a desired lift nothing but a pressure control (see curve in Figure 3) is needed, not e.g. a fast hydraulic control valve to stop in the right moment. On the contrary, the initiating solenoid valve only needs to have opened to its maximum flow area by the time the "flying" mass is in the middle of its stroke when flow is highest. Furthermore, due to the latching check valve, this hydraulic valve is allowed to stay open until some time later it is deenergized for initiating the closing of the gas exchange valve.

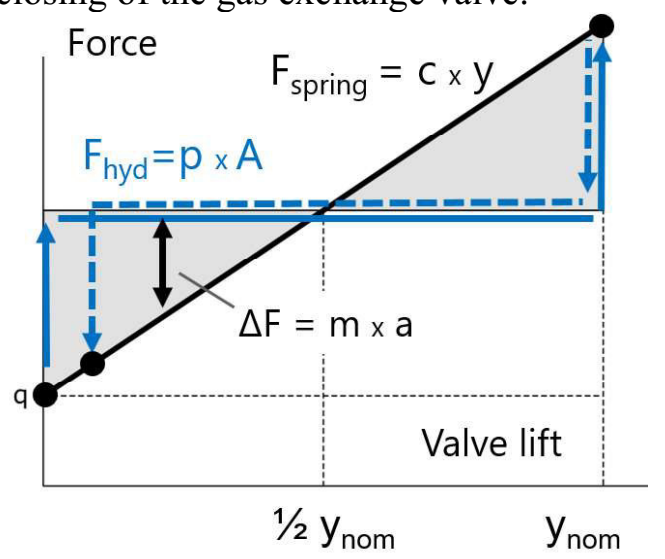

Figure 2: Force-stroke-diagram of an asymmetric hydraulic pendulum

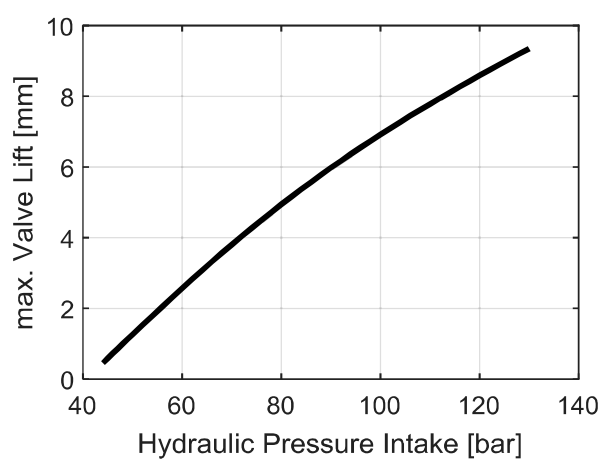

Figure 3: lift-pressure-assignment inlet valves

During closing it is not the pressure but the stored potential energy in the spring that accelerates the mass. The actuator piston works like a pump and 
recuperates. As no pendulum is ideal the gas exchange valve will not reach its closed position. At the end of recuperation (see Figure 4) a latching check valve keeps the mass safely in position (Figure 5b) before pressure deloading actuator cylinder brings the gas exchange valve back to the seat.

To find the right moment for deloading we can profit from the simple fact that the pendulum always needs about half period duration $T / 2$ for a single stroke - independently of direction, stroke length or dampening as is perfectly illustrated in Figure 4. A 2/2-deloading spool valve integrated in the main valve makes use of this predictable behaviour. and moves on its given pathway with constant speed (see Figure 5b) for opening the deloading channel to the low pressure accumulator precisely at the end of recuperation. The constant speed of the $2 / 2$-valve is generated by a typical hydraulic means: a spring acting on the spool surface to pump fluid through a fixed turbulent throttle orifice.

Landing on the valve seat (c in Figure 4 and Figure 5c) has to take place with a speed lower than $0.5 \mathrm{~m} / \mathrm{s}$. This happens stroke controlled: when the gas exchange valves come near the seat the actuator piston closes the main flow path by itself and the gas exchange valve spring generates a constant landing speed by pressing fluid through a resting throttling orifice.

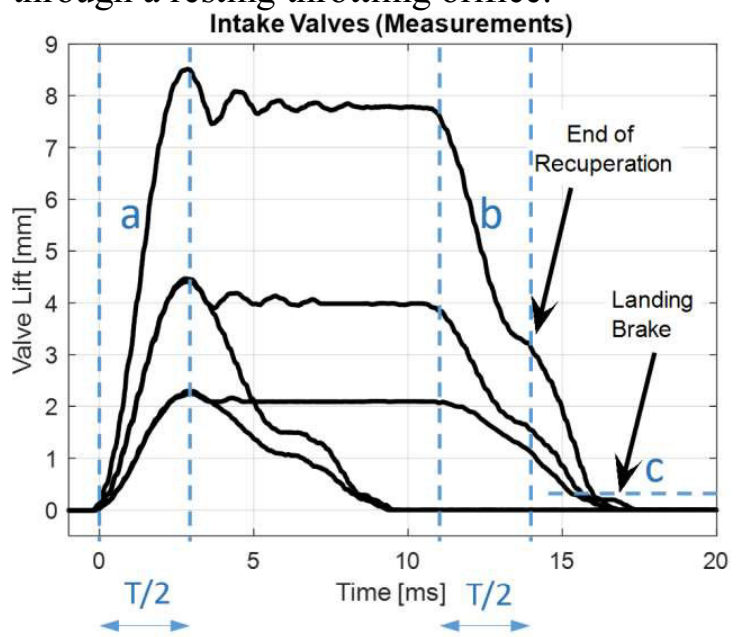

Figure 4: Lift curve sequences of intake valves at various lift heights and durations
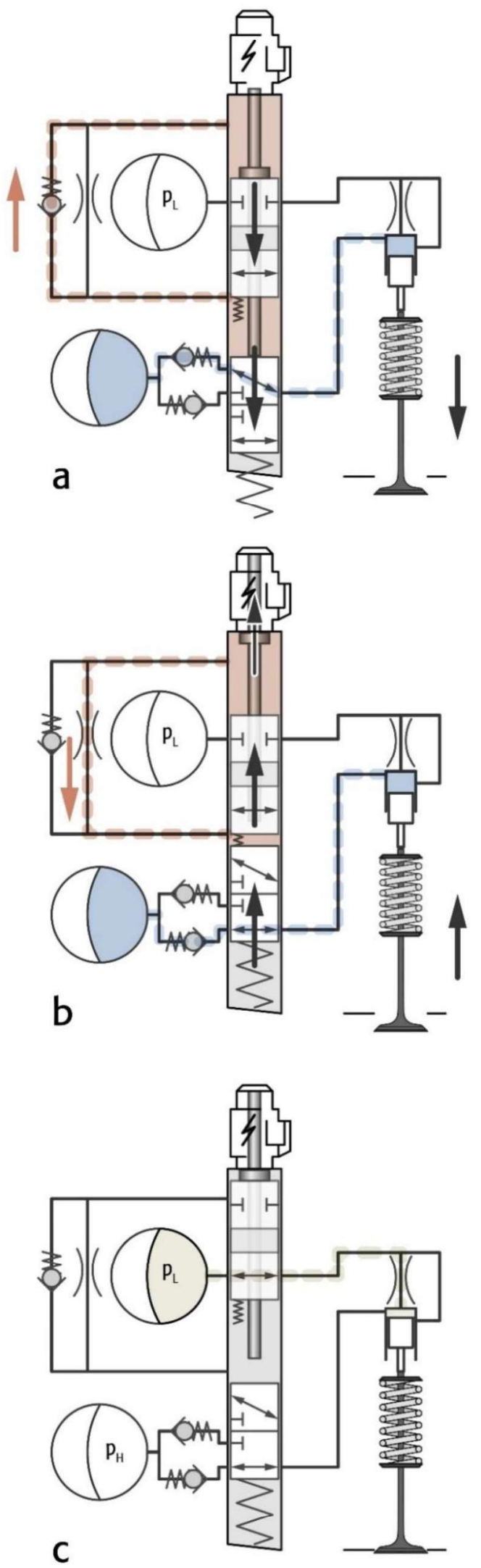

Figure 5: Hydraulic sequence control intake valve (source AUTO\&Technik, A. Lerch.) 


\subsection{Dimensioning}

Main parameter for the valve train is the periodic duration $\mathrm{T}$ which defines the minimum open time.

$$
T=2 \pi \times \sqrt{\frac{m}{c}}
$$

$\mathrm{m}$ is the total effective mass of two valves, two springs and spring disks, the valve bridge and the actuator piston. $\mathrm{c}$ is the spring constant of the combined spring.

$\mathrm{T}$ was chosen to about $3 \mathrm{~ms}$ according to the open time of the cam at top speed of the engine. The valve lift curve vs. crank angle at full speed would be quite similar to a cam based valve lift curve. In the most frequent low speed range this choice is sufficient for nicely sharp, near digital valve openings. The valve springs were chosen stiffer than the series springs. They still fit into the spring chamber, and have un endurant layout.

\subsection{Exhaust Valve Actuation}

Exhaust valves of combustion engines typically have to be opened against in-cylinder pressures of 5-15 bar (depending on engine type). The necessary energy input for operating the valves therefore is higher than for the inlet valves and cannot be recuperated completely.

With lift control by pressure as on the inlet valves an overshooting of the valves could happen in case of a combustion failure.

For this reason the exhaust valves are directly lift controlled by turnable actuator pistons with helical grooves for port control of the supply pressure. The fast moving actuator pistons cut off their own pressure supply according to their angular position which is controlled by a worm drive (Figure 6). On bottom of Figure 7 the stepper motor of the worm drive can be seen. Beginning of opening and closing still is controlled by the solenoid valves making cylinder deactivation possible also on the exhaust valves.

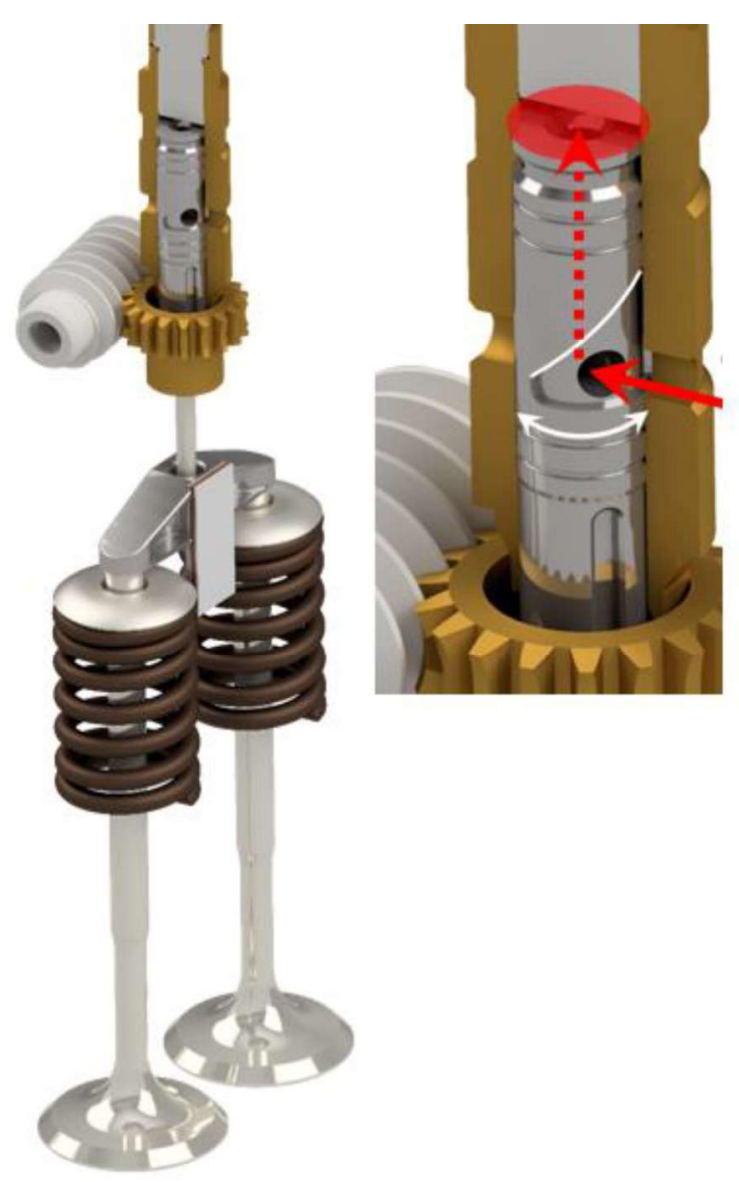

Figure 6: direct lift control mechnism of exhaust

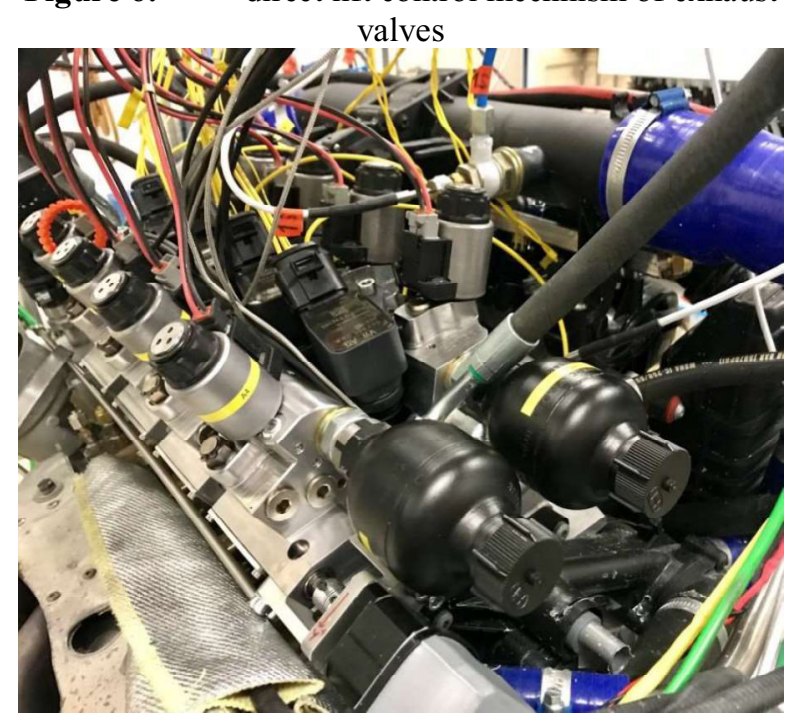

Figure 7: View on readily equipped cylinder head of the 1.41 SI passenger car engine (view along exhaust side)

\subsection{Fluid Choice}

Already pressurizing and depressurizing cylinder and channel volumes - yet without doing any work - is an inavoidable part of hydraulic cycles but always causes capacitive losses. These can 
only be minimized by either small (dead) volumes or by use of a low compressible fluid. As water-glycol features a high isentropic bulk modulus and is the standard cooling fluid of combustion engines, it was worth to try.

There are further advantages associated with this fluid like an oil free cylinder head. (Independently from that there is no need for cam drive lubricating additives which may shorten catalyst life.).

Two $6 \mathrm{~m}$ long spiral pipes were installed at the entrance and the exit of a first valve testing apparatus (Figure 8).

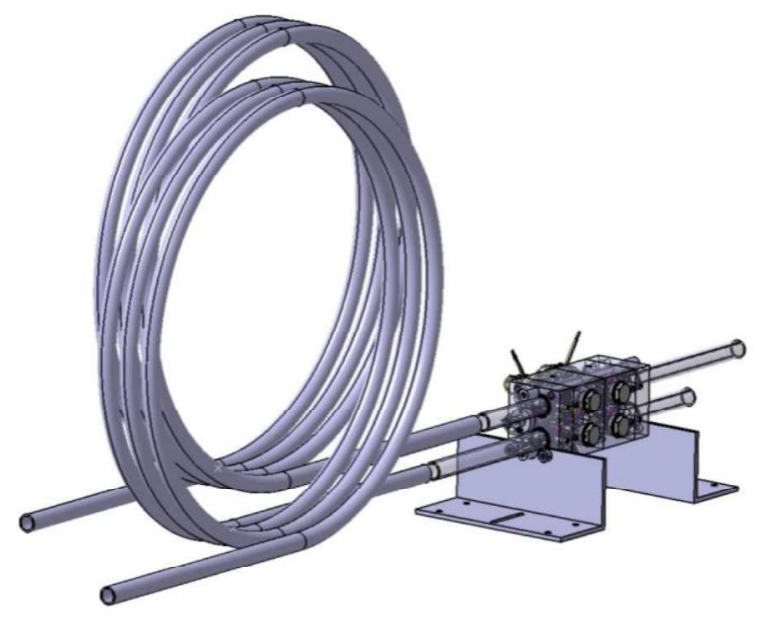

Figure 8: Pipe spirals for measuring fluid sound speed and dynamic flow

Detecting the pressure wave amplitude with a piezoelectric sensor allowed to measure directly the highly dynamic flow into the driving cylinder according (2):

$\frac{d Q}{d t}=\frac{A_{\text {Pipe }}}{\rho a} \times \frac{d p}{d t}$

A BASF 50:50 water glycol cooling liquid was used. The wave speed was determined from the reflected wave travel time to $1620 \mathrm{~m} / \mathrm{s}\left(@ 30^{\circ} \mathrm{C}\right.$, 140 bar). With the fluid density of 1075 the isentropic bulk modulus $E=\rho a^{2}$ was calculated to $28^{\prime} 200$ bar.

To maintain this high bulk modulus during operation it is mandatory to have a good deaeration. A low pressure level of 15 to $20 \mathrm{bar}$ keeps deaeration as well as cavitation on a non harming level.

\subsection{Hydraulic Component Choice}

\section{Solenoid Valves}

The solenoid valves have been constituted by seat valve elements of Bieri Hydraulik AG and pole tubes and slip-on coils from Hydac. The valve parts were press fitted to the housing in order to keep dead volumes small. However other ways of fitting seem possible. The pole tubes so far are not made from eddy-current surpressing steels.

Figure 9 gives a rough impression on the construction. The single valve actuations are assembled into in blocs which are connected to each other by hydraulic pipe pieces.

\section{Check Valves}

Market available standard screw-in check valves size $1 / 8$ " and $1 / 4$ " with slightly elevated cracking pressures were used.

\section{Pressure supply}

Pressure supply and control on both high pressure levels should finally be done by a variable flow pump, e.g. a two-circle piston pump with two suction controls. For todays setup the exhaust side of the hydraulic system is being pressurized (up to 200 bar) by a Diesel common rail pump and the inlet side by a conventional pure water pump, both high pressure levels are being controlled by Bieri proportional pressure relief valves. The low level pressure is retained by a mechanical pressure relief.

\section{Accumulators}

Hydac Accumulators of the smallest standard size $\left(75 \mathrm{~cm}^{3}\right)$ were used. They look big on Figure 7 but as will be explained below the size has no relevant impact on the engine dynamics as will be explained below. Nevertheless smaller accumulators would do as the maximum instantaneous fluid need of one cylinder only is half a $\mathrm{cm}^{3}$.

\section{Sensors}

Apart from the typical engine and hydraulic testing sensors for monitoring and control of the valve train were needed. ELGO inkremental magnetic strips were glued to the valve bridges. These sensors serve for lift measurement and only - slow adaptive control. 


\subsection{Power Electronics and Control}

The solenoids are controlled by a dspace microautobox. The rapid prototyping unit contains injection drivers with boost current capabilities as needed for the solenoid valves.

The own programming at Empa - low and hilevel control for all kinds of controls in Matlab/ Simulink - was helpful for a fast realization without restrictions.

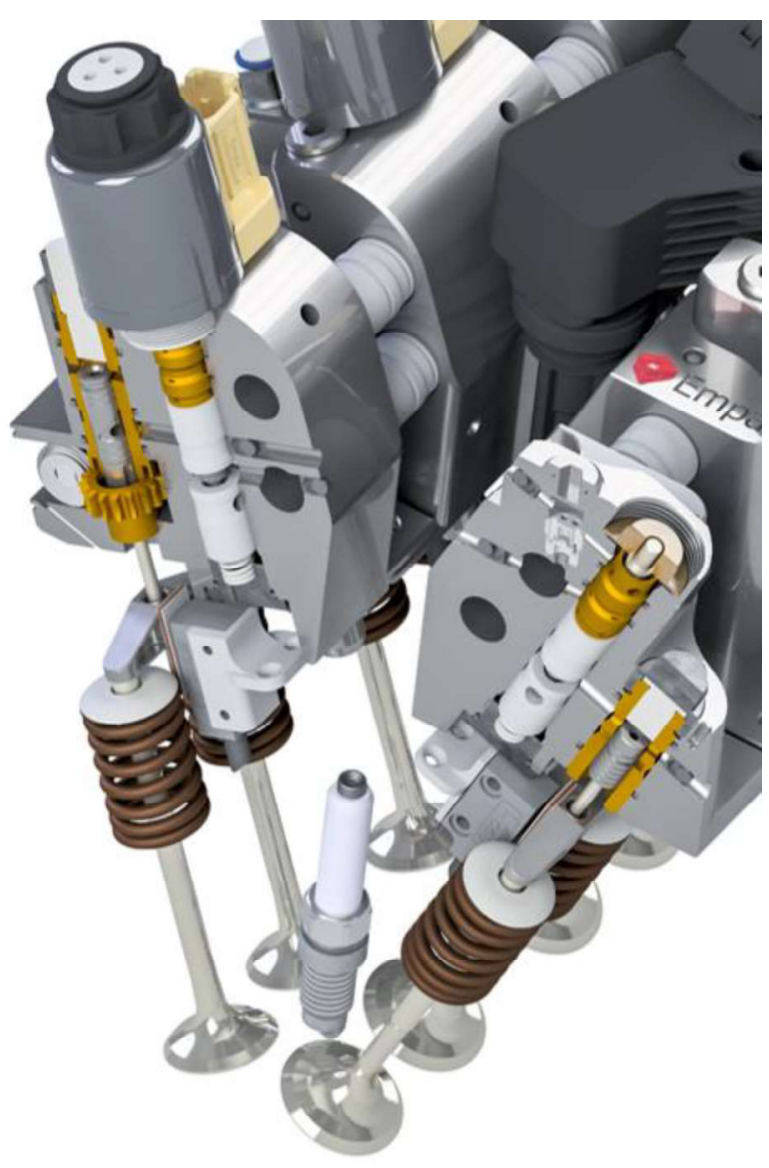

Figure 9: Valve train installation

\section{RESULTS AND EXPERIENCE}

The engine, a $1.41 \mathrm{VW}$ spark ignited engine, running on methane, has run $100 \mathrm{~h}$ in the new configuration. Due to the problemless functioning of the valve train Empa already has been able to do a lot of various measurments.

\subsection{Power demand of the Valve Train}

The hydraulic power need of the new valve train was measured (on the fired engine!) by measuring pressures and flows at taking into account an efficiency of $85 \%$ of variable displacement pressure supplies. As this engine has not been tested in the cam-version a typical value of 0.25 bar mean friction pressure is assumed. Published data on fired cam engines are extremely rare [11].

The low hydraulic energy effort is owed to the high recuperation rate. This was measured to be up to $60 \%$.

The electric power need has not yet been optimized for its task.
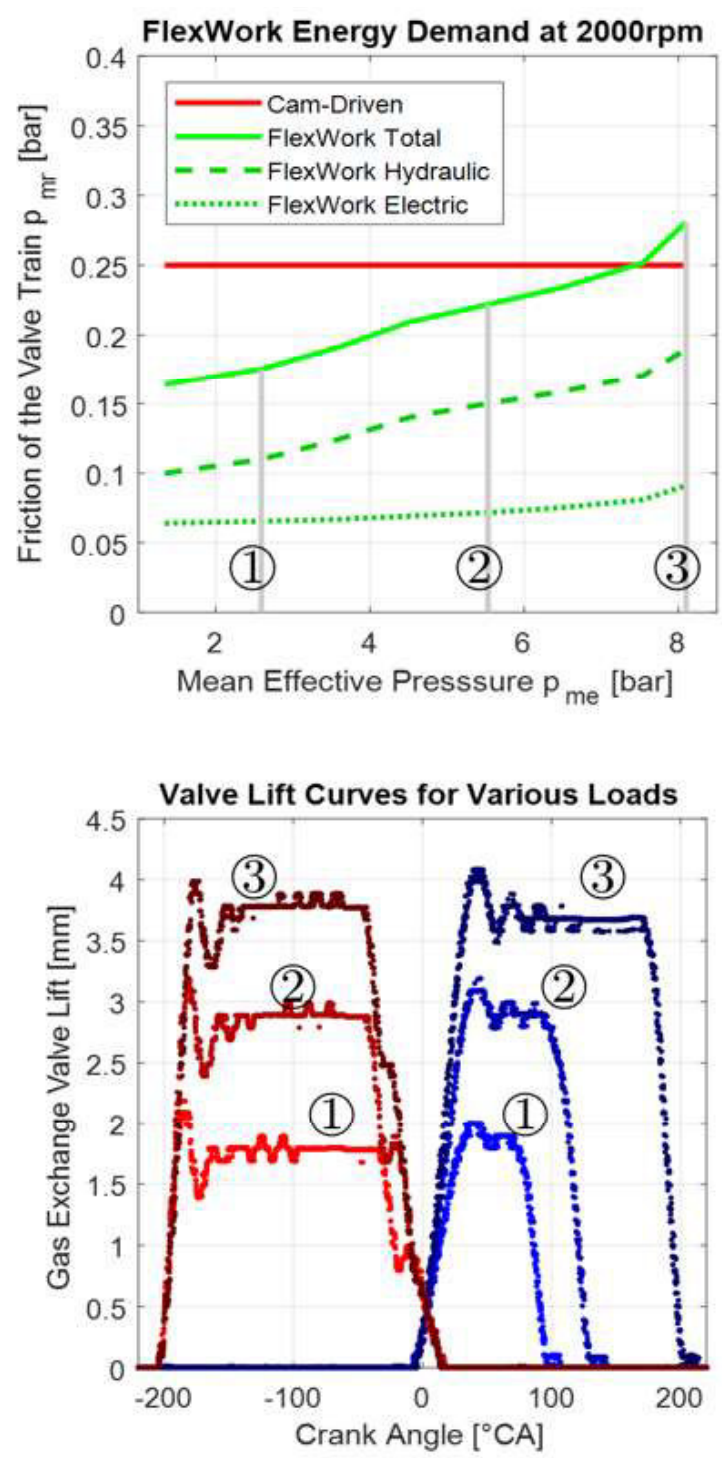

Figure 10: Valve Train energy demand and corresponding valve lift curves

\subsection{Experience with the Hydraulic Fluid}

Good results have been obtained with waterglycol as a low compressible hydraulic fluid. White-green coloured residues appear where the water evaporates on an open surface.. The choice 
of the kind of fluid however (cooling liquid, engine oil, diesel fuel, braking fluid) does not seem to be decisive for the total energy need, as in particular the electric energy need has not been optimized yet, see below.

As the system mostly is running at lower engine speeds the number of switchings of the valve train is about 4'000'000 cycles.

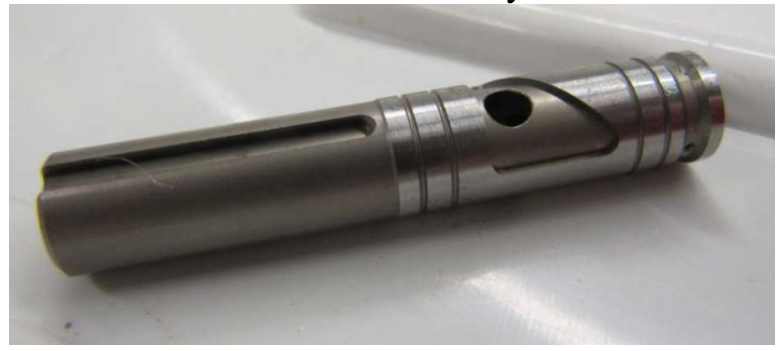

Figure 11: "Like new" helical groove actuator piston after first disassembling after 1 Mill. Cycles

Even the stems of the gas exchange valves which are not lubricated by engine oil anymore show no influence of the cooling liquid. This may be owed to the fact, that special attention was given to avoid side forces on the stem

\subsection{Test engine results}

Figure 12 significantly shows for a typical part load operating point how strongly the size of the negative gas exchange work loop can be minimized by unthrottled early intake closing. For the throttled case the still mounted engine throttle plate was closed to the necessary extent.

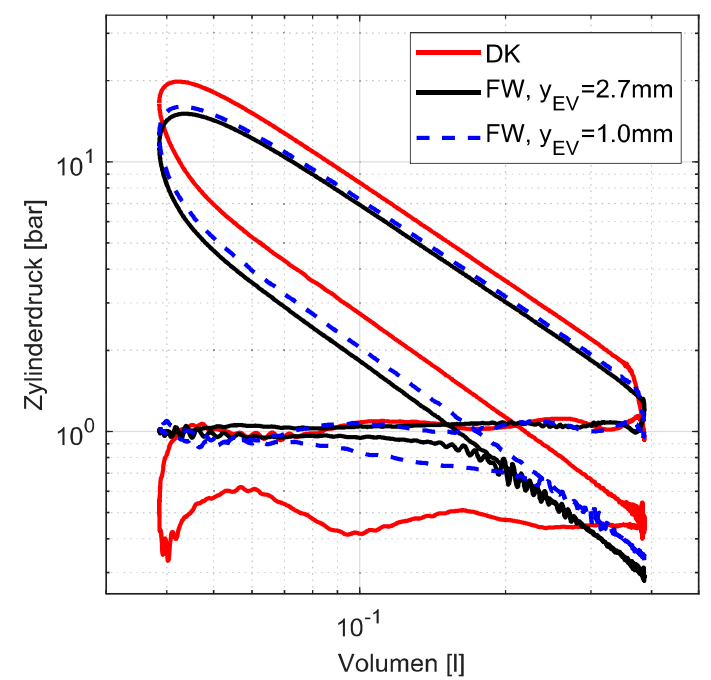

Figure 12: Measured logarithmic $\mathrm{pV}$-diagram on test engine: load control with early intake closing (FW, two valve lifts) versus throttle (DK)@ 2000 rpm/ 2 bar mean eff. pressure, efficiency gain $13.1 \%$
The diagram also shows there is little effect in opening the gas exchange valves more than adequate $(3 \mathrm{~mm})$ at this engine speed and that even at full load at this speed a much higher lift is not mandatory, as the suction losses cannot be reduced much more. So the time needed for pressure build up in the hydraulic accumulator will not in the least restrict the engine dynamics. On the contrary valve timings and therewith load changes can be switched not only within engine cycle time but in firing frequency [12], suprisingly faster than the engine reaction one is used to.

\subsection{Simulated driving cycles}

The stationary engine test results were transponed into a $\mathrm{CO}_{2}$ driving cycle effect by simulation [12]:

Table 1: Efficiency potential in new WLTP driving cycle of Flexwork (FW) engine in $1400 \mathrm{~kg}$

\begin{tabular}{ll}
\hline Engine & Efficiency gain [\%] \\
\hline Base line engine (throttled) & 0 \\
Flexwork engine & 6 \\
FW engine incl. cyl. deactivation & 8 \\
FW engine in hybrid car & 3 \\
FW engine in hybrid car incl. cyl. & 4 \\
deactivation &
\end{tabular}

The results are in so far conservative as the new World Light Vehicle Test Procedure (WLTP) has much less low load conditions as the older NEFZ. The results will improve with the weight of the cars. Also the geometric compression ratio of the test engine is not state of the art

\section{CONCLUSION AND OUTLOOK}

The newly developed flexible valve train showed impressing performance and efficiency improvements on the 1.41 Otto test engine and in subsequent driving cycle simulations. It has proven a reliable research tool and - thanks to its excellent and broad controllability - it will further support research work in the field of part load optimization of combustion engines and hybrid power train integration. It can also be used for optimising turbo charger integration, exhaust braking or for control of new low emission combustion concepts like Homogenous Charge Compression Ignition (HCCI) [12].

Due to its simplicity and robustness the question 
of chances to become a series product may be put.

The high achievable valve speeds make this valve train also suitable for load control of reciprocating gas compressors and expanders. Figure 13 shows simulated load variations on a reciprocating compressor and a reciprocating expander. At highest piston speed (half stroke) a fast - near digital - opening respective closing is specially important to keep throttle losses of the gas exchange to a minimum.

In continuation of these thoughts the fast electrohydraulic valve train may also help piston based Joule cycle engines and future Joule cycle based heat pumps (Figure 14) to become feasible.

The electrohydraulic system recuperates substiantial drive energy, up to $60 \%$, at closing of the gas exchange valves. The energy can be captured on the original supply pressure level and can directly be used for the next actuations.

Next step towards a convincing system could be the integration of the power supply which today still is external. May this system idea inspire other hydraulic applications in utilizing moving masses for energy recuperation.
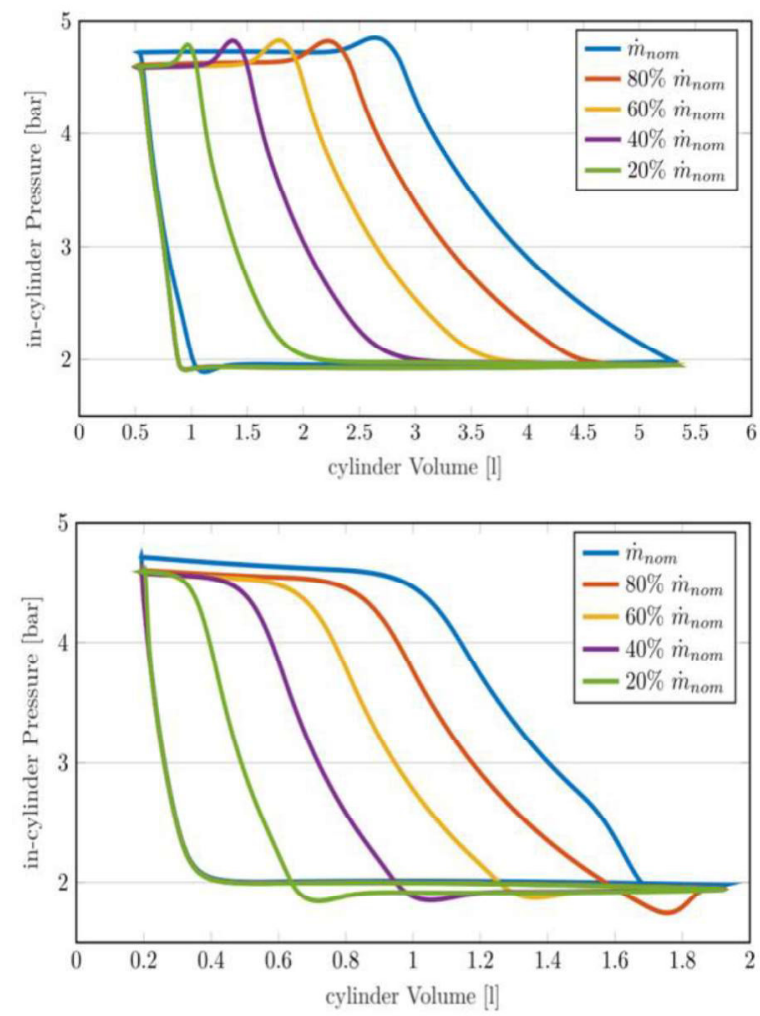

Figure 13: Simulated $p-V$-diagrams of load control on reciprocating gas compressor (top) and expander (bottom) by fast flexible valve train [13]

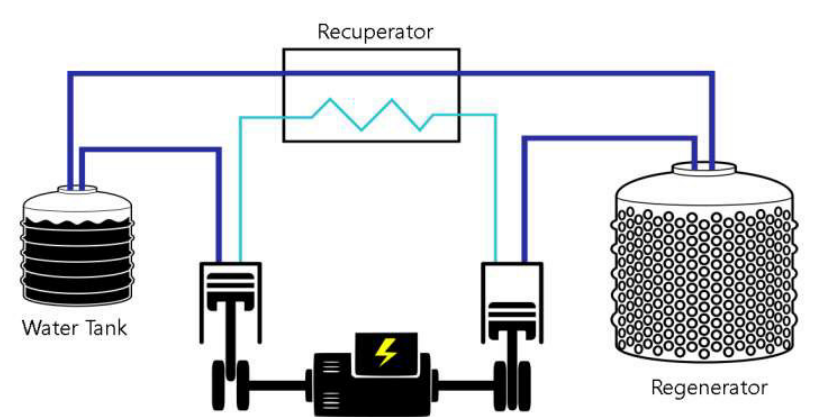

Figure 14: Electricity Storage System by Pumped Heat (ESSPH) [13]

\section{ACKNOWLEDGEMENTS}

The project "Flexwork" was made possible by the Swiss Federal office of energy. Preliminary work was supported by VSS-Lubes.

Bernhard Rüst pushed forward the developments with inspiring inputs on variable valve technologies.

Gratitude is also owed to the technology partners BASF, Bieri Hydraulics, Elgo Electronics, Mubea and Hydac with their straightforward help.

Warm thanks go to the whole Empa-team, particulary to name Andyn Omanovic, Norbert Zsiga, Patrik Soltic, Hugo Ehrensperger and Christian Bach who always made forget the work to be work.

\section{NOMENCLATURE}

$\rho \quad$ densitiy

$\omega \quad$ angular frequency

a sound speed

a acceleration

c spring constant

A Area

$E \quad$ Isentropic Bulk Modulus

$F \quad$ Force

$m$ mass

$n \quad$ engine speed

$p$ pressure

$t$ time

$Q \quad$ flow

period duration

$V \quad$ engine cylinder volume

$w \quad$ fluid flow speed

$y \quad$ Gas exchange valve lift 


\section{REFERENCES}

[1] Kirsten, K. (2011) Variabler Ventiltrieb im Spannungs-feld von Downsizing und Hybridantrieb. $32 . \quad$ Intern. Wiener Motorensymposium 2011

[2] Kreuter, P., Heuser, P., Schebitz, M. (1992) Strategies to Improve SI-Engine Performance by Means of Variable Intake Lift, Timing and Duration. SAE 920449

[3] Schechter, M.M., Levin, M.B. (1996) Camless Engine. SAE 960581

[4] Allen, J., Law, D. (2002) Production ElectroHydraulic Variable Valve-Train for a New Generation of I.C. Engines. SAE 2002-01-1109

[5] Turner, C. W., Babbitt, G.R., Balton, C. S., Raimao, M. A., Giordano, D. D. (2004) Design and Control of a Two-stage Electro-hydraulic Valve Actuation System. SAE 2004-01-1265

[6] Denger, D., Mischker, K. (2005) The ElectroHydraulic Valvetrain System EHVS - System and Potential. SAE 2005-01-0774

[7] Lou, Z. D. (2007) Camless Variable Valve Actuation Designs with Two-Spring Pendulum and Electrohydraulic Latching. SAE 2007-011295
[8] Battistoni, M., Foschini, L., Postrioti, L., Cristiani, M. (2007) Development of an ElectroHydraulic Camless VVA System. SAE 2007-240088

[9] Bernard, L., Ferrari, A., Micelli, D., Perotto, A., Rinolfi, R., Vattaneo, F. (2009) Elektrohydraulische Ventilsteuerung mit dem «MultiAir»-Verfahren. MTZ 70 (2009) 12, S. 892-899

[10] Möller Andreas (2019) Cam-Less Valve Train Opportunities - Implementing a Freevalve Valve Train in an automotive Application, 8. VDITagung Ventiltrieb und Zylinderkopf, Würzburg 2019

[11] Mufti, R.A., Priest, M.: Effect of cylinder pressure on engine valve-train friction under motored and fired conditions Proceedings of the Institution of Mechanical Engineers 2012 Part J: Journal of Engineering Tribology 226 (4), p. 306-314

[12] Zsiga, N., Omanovic, A., Soltic, P., Schneider, W. (2019) Funktionsweise und Potenziale eines neuartigen elektrohydraulischen Ventiltrieb, MTZ 9 (2019) S. 18-26

[13] Omanovic, A. (2018) Analysis and Optimization of an Electric Energy Storage System, Master Thesis ETH Zuerich 